\title{
Empirical Analysis and Countermeasures of Interprovincial Tax Transfer in China
}

\author{
Junjun Zhang ${ }^{1,2, \text {, }}$ Ke Gao ${ }^{3,4, *}$ \\ ${ }^{1}$ The School of Finance and Taxation, Central University of Finance and Economics, Beijing, P.R. China \\ ${ }^{2}$ Institute of Fiscal Science, Department of Finance, Guangxi Zhuang Autonomous Region, P.R. China \\ 3“The Belt and Road” Economic Development Research Center, Shandong University of Finance and Economics, Jinan, P. R. China \\ ${ }^{4}$ Development Research Center of Shandong, Jinan, P. R. China
}

Email address:

13907865848@163.com (Junjun Zhang),gkfly@126.com (Ke Gao)

*Corresponding author

\section{To cite this article:}

Junjun Zhang, Ke Gao. Empirical Analysis and Countermeasures of Interprovincial Tax Transfer in China. American Journal of Management Science and Engineering. Vol. 3, No. 5, 2018, pp. 53-59. doi: 10.11648/j.ajmse.20180305.13

Received: September 17, 2018; Accepted: October 18, 2018; Published: November 8, 2018

\begin{abstract}
The reform of the Tax-sharing System in China only regulates the vertical tax distribution relationship between the central government and the local government, but the horizontal tax distribution contradiction between the local governments is increasingly prominent. This paper takes China as an example, using data and empirical models, combined with theoretical analysis, discusses the problems of tax transfer and tax coordination among different regions in a country, which is essentially the problem of the deviation from tax and tax sources. This paper calculates the degree of deviation between regional tax and tax sources by the method of proportion difference, and makes an empirical analysis of the factors affecting tax transfer, including market size, labor cost, trade cost, urbanization level, degree of opening. It explains the phenomena, causes, impacts and harm on economic development of tax transfer among regions in China. Those impacts include: increasing regional disparities and hindering regional coordinated development, widening the gap in public services between regions, stimulating the irrational investment behavior and scale expansion of local governments, distorting economic indicators is not conducive to scientific decision-making, deteriorating the natural environment of the resource-providing place, influencing the construction of the harmonious society. Then make the suggestion that the macro level top-level design plan and policy should be adopted at the national level: improve the tax distribution system for horizontal transfer payments, improve the vertical financial transfer payment distribution system, reform the tax system appropriately according to the principle that the tax is consistent with the tax source, improve the tax collection and management system, improve the management of corporate consolidated tax payment, promote the reform of the price mechanism of resource elements and solving the problem of the resource pricing distortion, reform the performance evaluation indicators of local governments to prevent vicious tax competition, replace regional tax incentives with industrial tax incentives.
\end{abstract}

Keywords: Tax Transfer, Tax Deviation, Empirical Analysis

\section{Introduction}

In 1994, China began to implement the Tax-sharing System reform, and achieved good operational results. The central government and local governments have achieved huge growth in tax revenues, further rationalizing the vertical distribution of finance, and dividing the financial and business authorities of the central and local governments. With the financial power, the financial resources required by the central government and local governments to fulfill their powers are guaranteed. However, the Tax-sharing System only regulates the vertical fiscal-tax distribution relationship between the central government and local governments, and the contradiction between horizontal tax distribution among local governments is increasingly prominent [1]. In the Next step of establishing modern fiscal system, it not only needs to consider issues such as local taxation setting and levying as well as vertical transfer payments, but also needs to consider 
inter-regional tax transfers and tax coordination. The essence of this is the problem of deviation between taxation and tax sources [2].

\section{The Status and Problems of Inter-regional Tax Transfer in China}

From the statistical analysis, we can also see that there is a tax transfer( the deviation between tax and tax source ) between China's regions. Since the regional economy is the source of regional taxation, the total amount of economics of the same scale should provide the same amount of tax, so whether the tax and tax sources are deviated and the degree of deviation can be judged by the difference between the regional tax revenue and the regional economic aggregate (the proportion of a province's tax revenue to the total national tax revenue is compared with the proportion of the economy to the national economy) [3]. The regional economic aggregate is generally expressed in terms of gross domestic product (GDP). The total regional tax revenue is represented by the local level tax which belongs to the region after vertical distribution. Therefore, the formula for calculating the regional tax and tax source divergence using the proportional difference method can be designed as follows:

$$
S i=\frac{T i}{\sum_{i=1}^{n} T i}-\frac{G i}{\sum_{i=1}^{n} G i}
$$

Among them: $S^{i}$ is the taxation and tax source deviation of region $\mathrm{i}, \mathrm{T}^{\mathrm{i}}$ is the local tax of region $\mathrm{i}$, and $\mathrm{G}^{\mathrm{i}}$ is the regional GDP of region $i$ (excluding the added value of the primary industry, because the agricultural tax has been cancelled in China, the primary industry has little impact). If $S^{i}$ is greater than 0 , it indicates that the area is the tax transfer place (taxes are transferred to the area). If it is 0 , it indicates that the tax in the area is basically the same as the tax source. If it is less than 0 , it indicates that the area is the tax removal place (taxes are moved out of the area). The greater the absolute value of $S^{i}$, the greater the deviation of tax and tax sources in the region. According to the calculation, the following table is obtained (see Table 1). It can be seen from the table that the eastern provinces and municipalities are mostly net inflow areas, while the central and western regions are mostly net outflow areas.

Table 1. Taxation and tax source divergence in all provinces, autonomous regions and municipalities in China (\%).

\begin{tabular}{lllllll}
\hline District & $\mathbf{2 0 0 9}$ & $\mathbf{2 0 1 0}$ & $\mathbf{2 0 1 1}$ & $\mathbf{2 0 1 2}$ & $\mathbf{2 0 1 3}$ & $\begin{array}{l}\text { average } \\
\text { value }\end{array}$ \\
\hline East & 6.42 & 5.94 & 5.60 & 4.98 & 4.65 & 5.52 \\
Beijing & 3.67 & 3.36 & 3.54 & 3.22 & 3.15 & 3.39 \\
Tianjin & 0.11 & 0.09 & 0.09 & -0.09 & -0.04 & 0.03 \\
Hebei & -1.34 & -1.21 & -1.28 & -1.16 & -1.13 & -1.22 \\
Liaoning & 0.35 & 0.39 & 0.52 & 0.57 & 0.36 & 0.44 \\
Shanghai & 4.53 & 3.98 & 3.69 & 3.42 & 3.30 & 3.78 \\
Jiangsu & 0.40 & 0.32 & 0.32 & 0.45 & 0.37 & 0.37 \\
Zhejiang & 0.97 & 0.89 & 0.70 & 0.53 & 0.33 & 0.68 \\
\hline
\end{tabular}

\begin{tabular}{|c|c|c|c|c|c|c|}
\hline District & 2009 & 2010 & 2011 & 2012 & 2013 & $\begin{array}{l}\text { average } \\
\text { value }\end{array}$ \\
\hline Fujian & -0.37 & -0.42 & -0.31 & -0.38 & -0.26 & -0.35 \\
\hline Shandong & -2.71 & -2.40 & -2.40 & -2.28 & -2.16 & -2.39 \\
\hline Guangdong & 0.62 & 0.60 & 0.40 & 0.38 & 0.39 & 0.48 \\
\hline Hainan & 0.22 & 0.34 & 0.33 & 0.33 & 0.35 & 0.31 \\
\hline Centre & -5.61 & -5.77 & 5.65 & -5.06 & -4.60 & -3.08 \\
\hline Shanxi & 0.14 & -0.06 & -0.11 & 0.03 & 0.05 & 0.01 \\
\hline Jilin & -0.53 & -0.58 & -0.44 & -0.40 & 0.41 & -0.31 \\
\hline Heilongjiang & -0.55 & -0.58 & -0.49 & -0.44 & -0.38 & -0.49 \\
\hline Anhui & -0.19 & -0.03 & -0.11 & -0.11 & -0.09 & -0.11 \\
\hline Jiangxi & -0.34 & -0.29 & -0.29 & -0.11 & -0.03 & -0.21 \\
\hline Henan & -1.92 & -1.89 & -1.87 & -1.82 & -1.63 & -1.83 \\
\hline Hubei & -1.03 & -1.11 & -1.00 & -0.90 & -0.79 & -0.97 \\
\hline Hunan & -1.19 & -1.22 & -1.34 & -1.31 & -1.32 & -1.28 \\
\hline West & -0.81 & -0.17 & 0.04 & 0.08 & -0.05 & -0.18 \\
\hline Chongqing & -0.13 & 0.07 & 0.21 & 0.05 & 0.03 & 0.05 \\
\hline Szechwan & -0.22 & -0.10 & -0.07 & -0.06 & -0.08 & -0.11 \\
\hline Guizhou & 0.17 & 0.21 & 0.21 & 0.30 & 0.34 & 0.25 \\
\hline Yunnan & 0.55 & 0.60 & 0.57 & 0.60 & 0.54 & 0.57 \\
\hline Tibet & -0.04 & -0.03 & 0.00 & 0.03 & 0.01 & -0.01 \\
\hline Shaanxi & -0.20 & -0.13 & -0.11 & -0.10 & -0.20 & -0.15 \\
\hline Gansu & -0.20 & -0.21 & -0.22 & -0.19 & -0.17 & -0.20 \\
\hline Qinghai & -0.03 & -0.03 & -0.03 & -0.02 & -0.01 & -0.02 \\
\hline Ningxia & -0.02 & 0.00 & 0.03 & 0.03 & 0.03 & 0.01 \\
\hline Sinkiang & 0.09 & 0.17 & 0.29 & 0.30 & 0.33 & 0.24 \\
\hline Guangxi & -0.31 & -0.36 & -0.47 & -0.46 & -0.48 & -0.42 \\
\hline Inner Mongolia & -0.46 & -0.37 & -0.36 & -0.39 & -0.40 & -0.40 \\
\hline
\end{tabular}

Source: China Tax Yearbook, China Statistical Yearbook.

\section{Empirical Analysis of Relevant Factors Affecting Tax Transfer}

\subsection{The Choice of Variables and Their Meaning}

Explained variable: This paper uses the tax transfer statistics of each province and city measured in Table 1 to measure the degree of tax transfer between provinces and cities, expressed by $Y_{t}$.

Explanatory variables: According to the analysis of the tax transfer impact mechanism, the following variables can be selected to explain the influencing factors of tax transfer formation:

Market size ( mark $\left._{\mathrm{it}}\right)$ : When the microeconomic main body chooses the location, the market size is the most important consideration. Similarly, when companies and individuals choose to transfer taxes, they will also consider whether the region has formed scale economy and whether they can benefit from economies of scale. In addition, the market size also means the purchasing power of the region. The strong market demand is the guarantee to maximize the return on investment. Close to the large-scale market means that the transportation cost and related market search costs can be reduced, and the changes in market demand can be understood in time [4]. This paper uses the ratio of regional per capita GDP (GDP $\mathrm{Gi}_{\mathrm{it}}$ ) to national per capita gross domestic product (GDP) to measure the size of the market in the region. Generally speaking, the larger the market size, the more attractive the tax revenue is, that is, the market size has a positive effect on tax collection. However, in the case of high trade costs (crowding costs), companies tend to place their 
sites around large-scale markets to reduce transportation costs, which means that the estimated coefficient of market size may be negative.

Labor costs $\left(\right.$ wage $_{i t}$ ): Labor cost is an important factor affecting the flow of tax transfer between regions. One of the purposes of tax transfer for most enterprises and individuals is to achieve profit maximization through cost minimization. Cost factors include production cost, transaction cost, transportation cost, as well as information costs, etc. The labor cost in production costs is the focus of location research. Companies tend to invest in areas with lower wages to take advantage of cheap local labor, especially in labor-intensive industries, thereby saving production costs. However, enterprises are gradually shifting from labor-intensive to technology-intensive and capital-intensive industries, requiring a large number of high-quality talents as the basic reservation condition. Labor wages are one of the criteria for measuring high-quality talents. Generally speaking, areas with high wages are often favored by high-quality talents and become a pool of talents, which has a positive effect on tax transfers.

Trade costs $\left(\right.$ tcost $\left._{i t}\right)$ : A good regional infrastructure creates a good hard environment for the development of the regional economy. Perfect infrastructure conditions are of great significance for reducing production and trade costs and increasing the return on investment. Higher trade costs are repulsive to economic growth, which is not conducive to the geographical concentration of corporate economic activities and hinders tax transfers between regions [5]. This paper uses the regional traffic density indicators (the ratio of the railway operating mileage, the inland waterway mileage and the road mileage to the land area of the region) to measure the trade cost of the region.

Urbanization level $\left(\right.$ ubran $\left._{i t}\right)$ : The process of urbanization can be seen as the process of transferring labor-intensive technology to human capital-intensive technology. Urbanization can increase the degree of labor division and cooperation, and has a significant positive external effect on economic growth. This paper uses the proportion of urban population in each region to the total population of the local area to measure the speed of urbanization in each province and municipality.

Degree of openness $\left(\right.$ open $\left._{\text {it }}\right)$ : The degree of openness in a region determines the mobility degree of production factors in the region and across regions. Generally speaking, regions with high economic openness, high economic efficiency, fast economic development, and high potential for economic development are more likely to attract tax revenue. This paper uses the total import and export volume of each province to account for the degree of openness.

The meaning of the above explanatory variables is shown in Table 2 .

Table 2. The description of explanatory variables.

\begin{tabular}{|c|c|c|}
\hline Explaining variable & Indicator & Meaning of the indicator \\
\hline Market size & mark $_{\text {it }}$ & Per capita GDP of provinces and cities/ National per capita GDP \\
\hline Labor cost & wage $_{\text {it }}$ & Per capita salary level of employed persons in various provinces and cities \\
\hline Trade cost & tcost $_{i t}$ & $\begin{array}{l}\text { (Railway mileage of each province and city }+ \text { mileage of inland waterway }+ \text { highway mileage)/ } \\
\text { Land area in the area }\end{array}$ \\
\hline Urbanization level & ubran $_{\text {it }}$ & Urban population of each province and city / Total local population \\
\hline Degree of opening & open $_{\text {it }}$ & Total import and export volume of provinces and cities / Local GDP \\
\hline Interaction term & tcostmark $_{\text {it }}$ & Interaction between trade costs and market size \\
\hline
\end{tabular}

\subsection{Panel Data Estimation Model for the Factors Affecting Tax Transfer}

$$
\mathrm{Y}_{\mathrm{it}}=\lambda_{1} \text { mark }_{\mathrm{it}}+\lambda_{2} \text { wage }_{\mathrm{it}}+\lambda_{3} \text { tcost }_{\mathrm{it}}+\lambda_{4} \mathrm{ubran}_{\mathrm{it}}+\lambda_{5} \text { open }_{\mathrm{it}}+\lambda_{6} \mathrm{tcostmark}_{\mathrm{it}}+\varepsilon_{\mathrm{it}}
$$

Where, $Y_{i t}$ is the degree of tax transfer, $\lambda$ is the regression coefficient, $\varepsilon_{i t}$ is the random error term vector. Perform ordinary least squares (OLS) estimation on the model, and the following estimation model is obtained:

$$
\mathrm{Y}_{\mathrm{it}}=\underset{(-5.6479)}{-1.3226 \text { mark }_{\mathrm{it}}}+\underset{(4.8076)}{0.000025 \text { wage }_{\mathrm{it}}}+\underset{(-11.8947)}{0.0215 \mathrm{tcost}_{\mathrm{it}}}+\underset{(2.0464)}{0.7203 \mathrm{ubran}_{\mathrm{it}}}+\underset{(6.6052)}{2.11 \text { open }_{\mathrm{it}}}+\begin{gathered}
0.0142 \mathrm{tcostmark}_{\mathrm{it}} \\
(8.9119)
\end{gathered}+\varepsilon_{\mathrm{it}}
$$

Table 3. Tax transfer agglomeration and difference influencing factors OLS estimation results $Y_{i t}$.

\begin{tabular}{llll}
\hline $\mathbf{Y}_{\text {it }}$ & & & \\
\hline Variable & Coefficient & T-value & P value \\
\hline mark $_{\text {it }}$ & -1.3226 & -5.6479 & 0.0000 \\
wage $_{\text {it }}$ & 0.0000 & 4.8076 & 0.0000 \\
tcost $_{\text {it }}$ & -0.0215 & -11.8947 & 0.0000 \\
ubran $_{\text {it }}$ & 0.7203 & 2.0464 & 0.0422 \\
open $_{\text {it }}$ & 2.1100 & 6.6052 & 0.0000 \\
tcostmark $_{\text {it }}$ & 0.0142 & 8.9119 & 0.0000 \\
Adj.R & 0.7490 & & \\
AIC & 2.2288 & & \\
SC & 2.3328 & & \\
DW & 1.9684 & & \\
\hline
\end{tabular}

The $\mathrm{T}$ statistic is inside brackets and the number of samples is 186 . The regression results show that the model's goodness of fit reaches $74.90 \%$, indicating that the model is overall significant, and each variable has passed the significance test at $5 \%$. This shows that all variables including market size, trade cost, urbanization level and openness are important factors affecting the Regional agglomeration and difference of tax transfer in China. The specific estimation results are shown in Table 3.

From the estimation results in Table 3, it can be seen that the estimated coefficient of market size $\left(\operatorname{mark}_{\mathrm{it}}\right)$ is negative, indicating that the agglomeration effect of market size on tax transfer is affected by trade costs, and the expansion of market 
size in a particular region will inevitably lead to congestion, such as Traffic congestion, excessive living environment, etc., which will have a negative external impact on society. Crowded negative externalities increase the trade costs between trade entities, partially or completely offsetting the effects of market size expansion. When the cost of trade in a large-scale market is high, companies tend to place their sites around them to reduce trade costs. In this case, the size of the market has a negative effect on the agglomeration of tax transfers. The trade cost $\left(\right.$ tcost $\left._{i t}\right)$ is negatively correlated with the agglomeration of tax transfers, that is, the higher the trade cost, the more unfavorable the transfer of tax between regions. The level of labor wages (wage it $_{\text {}}$ ) has a positive effect on tax transfers. If the wages are higher, the attraction to high-quality talents are greater, which is conducive to the regional transfer of taxation. The degree of openness $\left(\right.$ open $\left._{i t}\right)$ has a positive effect on tax transfer. The higher the degree of openness, the better the infrastructure and market economic system, the higher the efficiency of resource allocation, and the smaller the transaction cost of economic actors. Therefore, under the same conditions, taxes are more likely to be concentrated in the more open eastern coastal cities and the southwestern border areas facing Southeast Asian countries, such as Beijing, Tianjin, Shanghai, Jiangsu, Zhejiang, Hainan and Yunnan. The interaction between market size and trade cost ( tcostmark $\left._{i t}\right)$ also has an important impact on tax transfer. If the expansion of market size is conducive to reducing trade costs, the synergy between the two has a positive impact on tax transfer, which is conducive to the accumulation of tax transfers. In addition, urbanization $\left(\mathrm{ubran}_{\mathrm{it}}\right)$ is also one of the important factors affecting tax transfer, but its role is slightly weaker than the other variables.

\section{The Impact and Harm of the Deviation from Tax and Tax Source on Economic Development}

The problem of inter-regional tax transfer and tax coordination exists between countries, within a country, and even within a province. This paper mainly discusses tax transfer and tax coordination between provinces (autonomous regions and municipalities). The cross-provincial transfer of taxation violates the principle that tax and tax source are consistent, distorts the incentive mechanism of economic activities, affects the regional allocation of economic factors such as capital and labor, and expands the gap between regional financial resources and public services, making differences in the regional economic development potential, which cause macroeconomic fluctuations, also affect economic integration and the overall development of the country. Specifically, it has the following effects:

\subsection{Increasing Regional Disparities and Hindering Regional Coordinated Development}

The horizontal transfer of tax between regions is not conducive to mobilizing the subjective enthusiasm of local government economic development. It will also objectively reduce the ability of governments with net tax removal to improve the economic soft environment, and will intensify the shift of high-quality resources and factors from economically backward regions to economically developed regions. The shifting trend will further widen the existing inter-regional economic development gap, aggravating the imbalance in the development of financial resources between regions. Most of the registration places of the head office are established in developed areas, and the sub-institutions are often in resource-producing areas or underdeveloped areas, which objectively forms an unreasonable situation in which taxation is transferred from underdeveloped to developed regions, from the area of resource supply transferred to the area of resource use [6].

\subsection{Widening the Gap in Public Services Between Regions}

The enterprise tax is the reasonable price paid by the enterprise for the use of local natural and social resources to enjoy the public goods and services of the place where the enterprise is produced and managed, which should be paid to the local government where its actual economic activities are located. The existence of horizontal transfer of inter-regional taxation reduces the fiscal revenue of the government with a net tax removal and restricts the level of its provision of public goods and services. The government that has the tax outflow has the power of office but lacks the corresponding financial resources, which widens the gap between public services in the region.

\subsection{Stimulating the Irrational Investment Behavior and Scale Expansion of Local Governments}

In the case of horizontal tax transfer, local governments want to increase local tax revenue as much as possible, and transfer the tax income to the region. In order to develop the economy, increase fiscal revenue, and improve political performance, many local governments have made a fuss about the "preferential policies" for attracting foreign investment, attracting foreign enterprises to invest locally, and unilaterally pursuing investment scale, economic output value and fiscal revenue [7]. It is often overlooked whether the economic construction that attracts investment is in line with the development of the local industrial structure, whether it is in line with its own economic development planning and resource advantages, and whether it will cause pollution to the local area.

\subsection{Distorting Economic Indicators Is Not Conducive to Scientific Decision-making}

From the micro level, it is difficult for enterprises to obtain the required public services in the tax outflow, which is not conducive to the division of labor and coordination among different enterprises in the industry chain. The problems of resource-based enterprise income and ecological protection cannot be effectively solved. From the macro level, taxation and tax sources deviate, GDP and tax revenue misplacement 
are not conducive to judging the true macro tax burden of each region and the correlation between fiscal revenue and regional GDP [8]. Unreal economic operating data will also adversely affect the economic situation judgments and decisions of government departments at all levels.

\subsection{Deteriorating the Natural Environment of the Resource-Providing Place}

Resource areas are generally extensive management, resource utilization is low, and local governments have a heavier financial expenditure on resource conservation and ecological environment governance. However, underdeveloped areas are often resource-providing areas. In the case of exporting resources, polluting the environment, and destroying the ecology, taxes transfer will cause the situation to deteriorate further.

\subsection{Influencing the Construction of the Harmonious Society}

To achieve coordinated development of the regional economy and build the harmonious society is our development goal. However, the goal of each region is to accelerate the economic development of the region, thereby inducing disorderly tax competition among local governments and disrupting the market economic order. The problem of regional taxation and tax source divergence, standing in different positions, leads to different views in different regions. The government of tax removal has strongly urged that this problem should be solved, but the government of tax transfer is not willing to face up in order to protect the vested interests.

In short, whether from the perspective of fairness or efficiency, the deviation of taxation and tax sources is unfavorable for regional coordinated development and even the overall development of the country. First, from the perspective of fairness, the deviation of taxation and tax sources will directly lead to unfair regional tax distribution, affect the level of public financial resources between regions, and restrict the ability of different regions to provide public services, resulting in unreasonable gaps in tax revenues between different local governments and the "Matthew effect" of the strong and weak. Second, from the perspective of efficiency, taxation and tax source divergence will indirectly affect the behavior of economic entities, especially local governments, leading to disorderly tax competition and hindering the coordinated development of regional economies. On the other hand, it will encourage local governments to irrational investment behavior and expansion of scale, while distorting economic indicators, interferes with the optimal allocation of market resources between regions. Therefore, it is necessary to carefully study the issue of regional tax transfer, formulate a rational and standardized horizontal tax distribution method and tax coordination mechanism, narrow the degree of regional taxation and tax source deviation, and promote the coordinated development of regional economic and society.

\section{Conclusion and Suggestion}

The phenomenon of tax transfer of different areas is widespread in China. The difference between economically developed areas and economically underdeveloped areas is obvious. The degree of deviation can be measured. Its formation and influencing factors can be verified by empirical analysis. The deviation of tax and tax sources has influence and harm to economic development. Measures must be taken to adjust and handle this deviation.

Starting from the national central government, there should be a global rule and attention to the problem. It requires the top-level design of the country. It needs to learn from foreign experience and formulate relevant policies from the perspective of local inconvenience or inability. It should be considered mainly from the perspective of tax reform, government coordination and financial distribution. While carrying out the tax reform, paying attention to the construction of the local tax system, and lowering the power of taxation, do not neglect the horizontal tax transfer and tax adjustment between regions. It should be taken into consideration and incorporated into the overall plan.

\subsection{Improve the Tax Distribution System for Horizontal Transfer Payments}

China's current tax system does not regard tax attribution as one of the elements of taxation. The central government should reform the horizontal distribution system of taxation as soon as possible, and lay a good institutional foundation for solving the problem of taxation and tax source deviation through the reform of the basic tax system. Horizontal tax transfer allocation is divided into two cases. First of all, it can be negotiated by the relevant regional governments, based on the contribution to the tax source, make the horizontal distribution of tax revenue. Secondly, if there are a large number of relevant tax stakeholders and the negotiation cost is high, at this time, the taxation distribution formula can be formulated by the higher-level government departments according to the contribution of the local governments to the tax sources. According to the formula, the allocation among different regional governments is carried out. The income tax transfer caused by the summary tax payment can be resolved through this method. Special agencies should be set up to specialize in regional tax allocation and coordinate tax administration among local governments to resolve disputes over horizontal tax allocation [9].

\subsection{Improve the Vertical Financial Transfer Payment Distribution System}

The tax transfer caused by the turnover tax system is not clear and difficult to identify, but it exists objectively. In the long run, it should be rationalized by constructing a local tax system by optimizing the allocation of tax rights (including income rights). The tax base which is weak in liquidity and difficult to generate the output effect of taxation will be returned to the local [10]. Taxes that are easy to flow are placed under the central government, and tax transfers are 
internalized at the national level. It is necessary to strengthen the transfer payment system for the western regions with underdeveloped infrastructure and low level of regional development, and for the central regions with prominent tax removal and low macro tax burdens, and establish a transfer payment system with equalization of finance.

\subsection{Reform the Tax System Appropriately According to the Principle That the Tax Is Consistent with the Tax Source}

We should seize the opportunity of a new round of tax reform and reform the current basic tax system in accordance with the principle that taxation and tax sources are consistent. The income attribution should be included in the tax system elements, so that it can be equal to the existing tax system elements such as taxpayers, taxation objects, tax rates, taxation locations, tax preferences, etc., to avoid the confusion between income attribution and tax place, and the unclear principle of regional tax division [11].

\subsection{Improve the Tax Collection and Management System}

China's tax authorities are mainly set up according to administrative divisions. This kind of tax collection and management system with administrative boundaries as the boundary has been difficult to adapt to the complicated situation of cross-regional and cross-industry flow penetration of tax sources. We must explore a tax collection and management system that is compatible with economic realities. For example, on the basis of adhering to the current fiscal and taxation management system, the tax source management institutions shall be set up according to the taxpayer's scale, industry, and specific business, and the tax sources shall be classified and managed according to the structure and its risk characteristics [12]. Another example is the implementation of specialized management of large enterprises, which is not only a solution to the problem of "collecting taxes", but also a necessary means of "dividing taxes". With the rapid development of informatization, the spatial distance no longer constitutes an obstacle for the tax authorities to monitor the tax source information.

\subsection{Improve the Management of Corporate Consolidated Tax Payment}

In order to solve the problem of cross-regional transfer of corporate income tax under the income-sharing system of central and local shared taxation, it is necessary to further improve the current management of consolidated tax payment. It is necessary to further improve the current corporate consolidated tax payment management. For example, we should make use of fiscal adjustment to supplement and perfect the regional transfer of enterprise income tax. After the completion of the annual settlement of enterprise income tax, the central finance divides the consolidated enterprise income tax in the central treasury into parts and distributes them among provinces and municipalities according to the prescribed coefficients and the specific situation of the annual tax revenue growth [13].

\subsection{Promote the Reform of the Price Mechanism of Resource Elements and Solving the Problem of the Resource Pricing Distortion}

Regional tax transfers arising from government pricing deviating from market prices should be gradually resolved through market-based price reforms of resource products. To solve the problem of horizontal transfer of tax sources and imbalance of horizontal distribution of tax caused by resource elements, it is necessary to reform the pricing mechanism of resource elements and give full play to the role of market mechanisms in the pricing of resource elements [14]. Therefore, it is necessary to reform the price factor formation mechanism of resource elements, gradually loosen the administrative control over the price of resource elements, and give full play to the basic role of market mechanisms in resource pricing.

\subsection{Reform the Performance Evaluation Indicators of Local Governments to Prevent Vicious Tax Competition}

First, the performance evaluation index system of local governments and the "tax task" assessment indicators should be reformed to avoid local officials using irrational means to compete for tax sources. Second, we must oppose local protectionism, and strengthen regional economic exchanges to promote sustained and healthy economic development. It is necessary to urge local governments to shift the way to increase tax revenue from vicious competition to the way to develop the economy and enlarge the "cake." Economic development is the source of tax growth, and only long-term economic development can provide a sustainable and stable source of tax. Therefore, local governments should strengthen economic cooperation under the coordination of the central government, strive to enlarge the economic cake, and let each region get more "cakes" instead of competing for shares in a limited "cake".

\subsection{Replace Regional Tax Incentives with Industrial Tax Incentives}

Establish a policy of replacing regional tax incentives led by industrial adjustment, and abolish the preferential tax policies implemented in the previous year. Divide the industries of different nature according to the planning of industrial policy development in China, and implement different tax preferential policies. This will create a more equitable competition for local governments, and improve the situation of enterprises choosing more developed areas because of the difference between regional preferential tax policies and economic development. 


\section{References}

[1] Zhang Chunyu. Research on the tax relations between the central government and the provincial local government [D].Shengyang: Northeast university of finance and economics, 2017, 6 .

[2] Forest tenure, Zhang Gemeng. Research on the problems and countermeasures of regional tax transfer in $\mathrm{China}[\mathrm{J}]$. Knowledge economy, 2018, 02:28-30.

[3] Li Jianjun, Wang Ruixiang. Who benefits from the intergovernmental tax division? -- Based on the analysis of tax deviation and tax benefit [J]. Financial issues research, 2018, 1: 76-83.

[4] Yuan Jiao. Spatial econometric empirical study on regional agglomeration and difference of tax transfer [D]. Kunming: Yunnan university of finance and economics, 2013.

[5] Jiang Wei. Location decision of FDI in China: Spatial econometric analysis based on "third-party effect" [J]. World economic research, 2012, 01:75-80.

[6] Liu Yeting. A study on the horizontal transfer of tax between regions in China -Taking enterprise income tax and value-added tax as the main measurements basis[D]. Hefei: Anhui University, 2012.

[7] Chen Wenbin. Study on the deviation of tax sources and the horizontal distribution of taxes between regions in China [D]. Jinan : Jinan University, 2012.

[8] Li Chunying. Study on horizontal transfer of taxation in China [D]. Changsha: Hunan university, 2013.

[9] Liu Jianhui, Tang Wenqian, Zhou Zhibo. Causes and countermeasures of unbalanced horizontal tax distribution in China[J]. Tax research, 2012, 2: 41-43.

[10] Wang Lingmiao. Problems and countermeasures of regional tax transfer in China [D]. Shenyang: Liaoning university, 2013.

[11] Luo Siping. Reference to China's tax source management from international experience[J]. Economic research guide, 2011, 18: 19-20.

[12] Wang Min, Yuan Jiao. Asymmetry between regional taxation and tax source: Impact mechanism and realistic path selection [J] Tax research, 2017, 5: 59-63.

[13] Dong Zaiping. A study of regional tax transfer in China from the perspective of fiscal decentralization[J]. Reform of the economic system, 2009, (2): 121-125.

[14] Yang Xianyue. Research on the adjustment of transfer pricing of affiliated enterprises and countermeasures [J]. China foreign capital, 2013, 4:23-24. 